\title{
ASPECTOS DA CADEIA PRODUTIVA MOVELEIRA DO BRASIL E O RIO GRANDE DO SUL NESSE CONTEXTO
}

\author{
Aspects of the brazilian furniture production chain and the state of Rio \\ Grande do Sul in this context
}

Karine Matuchevski Balzan'; Argemiro Luis Brum²; Dilson Trennpohl³; Romualdo Kohler ${ }^{4}$

\begin{abstract}
1Doutoranda do curso de Desenvolvimento Regional da UNIJUÍ. E-mail: kmatucha@hotmail.com
${ }^{2}$ Professor nos cursos de Mestrado e Doutorado em Desenvolvimento Regional da UNIJUí, doutor pela EHESS (Paris, França).E-mail: argelbrum@unijui.edu.br

${ }^{3}$ Professor nos cursos de Mestrado e Doutorado em Desenvolvimento Regional da UNIJUÍ, doutor em Desenvolvimento Regional pela UNISC.E-mail: dilson@unijui.edu.br

${ }^{4}$ Professor nos cursos de Mestrado e Doutorado em Desenvolvimento Regional da UNIJUÍ, doutor em Administração pela UNaM (Misiones, Argentina).E-mail: romualdo@unijui.edu.br
\end{abstract}

Data do recebimento: 24/07/2019 - Data do aceite: 04/05/2020

RESUMO: A importância do setor moveleiro na economia brasileira pode ser observada por meio de sua capacidade de geração de empregos, distribuídos pelo território nacional e pelas enormes ligações direta e indireta de sua cadeia produtiva. Tendo em vista este cenário, o objetivo deste artigo foi a elaboração de uma estrutura da cadeia moveleira no Brasil em geral e no Rio Grande do Sul em particular. Para isso, foi realizada uma revisão bibliográfica em livros, revistas, teses, dissertações, relatórios e artigos da área. Desenvolveu-se o desenho da cadeia produtiva, com os seus elos e caracterizações, enfatizando seus fornecedores primários, secundários e o mercado consumidor. $\mathrm{O}$ estudo mostrou que a indústria de móveis se apresenta bem distribuída, havendo algumas regiões mais desenvolvidas do que outras, as quais concentram a maioria dos empregos formais do setor, o que contribui muito para o desenvolvimento das regiões onde estão inseridas tais empresas.

Palavras-chave: Cadeia Produtiva. Setor Moveleiro. Rio Grande do Sul.

ABSTRACT: The importance of the furniture sector in the Brazilian economy can be seen through its capacity to generate jobs, distributed throughout the 
national territory and the enormous direct and indirect connection of its production chain. In view of this scenario, the objective of this article was to elaborate a structure of the furniture chain in Brazil in general and in Rio Grande do Sul state, in particular. A bibliographic review was carried out on books, magazines, theses, dissertations, reports and articles in the area. The design of the production chain was developed with its links and characterizations, emphasizing its primary, secondary suppliers and the consumer market. The study showed that the furniture industry is well distributed, presenting some regions more developed than others, which concentrate most of the formal jobs in the sector, which contributes a lot to the development of the regions where these companies are inserted.

Keywords: Productive Chain. Furniture Industry. Rio Grande do Sul.

\section{Introdução}

A importância da cadeia produtiva moveleira no Brasil em geral e no Rio Grande do Sul em particular se encontra, dentre outras coisas, na elevada geração de emprego e circulação de renda por ela proporcionada por meio dos seus diferentes elos.

Nas últimas décadas, diversos fatores têm contribuído para o surgimento e ampliação das cadeias produtivas. Dentre eles, é possível destacar o acirramento da competitividade, conduzindo a otimização do relacionamento entre as empresas; a expansão do uso da tecnologia da informação; e o estabelecimento de parcerias comerciais.

Nesse contexto, a cadeia produtiva moveleira vem apresentando crescimento considerável nos últimos anos, sendo alvo da atenção de diversos segmentos da área governamental em virtude de suas possibilidades na geração de divisas e na criação de novos empregos. A disponibilidade de matéria-prima e mão de obra, além da experiência acumulada nos polos existentes nas regiões Sul e Sudeste, são fatores que contribuem para o crescimento desse setor.
O estado do Rio Grande do Sul é um dos maiores polos moveleiros do Brasil, sendo que, em sua região Fronteira Noroeste (conforme divisão estabelecida para os Conselhos Regionais de Desenvolvimento junto ao governo do estado), a indústria de móveis é considerada como uma das mais importantes atividades, constituindo-se, aos poucos, em um polo industrial na produção de móveis no estado gaúcho.

Este artigo apresenta como objetivo a elaboração de uma estrutura da cadeia moveleira no Brasil em geral e no Rio Grande do Sul em particular. Para isso, foi realizada uma revisão bibliográfica com autores conceituados da área, que tratam particularmente da cadeia produtiva moveleira gaúcha, apresentando seus principais elos e sua contribuição para o desenvolvimento regional.

\section{Cadeia Produtiva}

Cadeia produtiva, conforme Costa e Nunez (2017), refere-se a produto, bem ou serviço, interligados a uma sequência de procedimentos realizados por várias unidades. Trata-se de atividades que vêm desde a pro- 
dução, passando por distribuição e circulação até o consumo.

Selmani (1992) define a cadeia produtiva como sendo uma sequência de modificações que ocorrem com a matéria-prima. Esta sequência vem desde a extração da matéria-prima no seu ambiente natural, passando pelas etapas da produção, de consumo, de recuperação e de eliminação.

Castro et al. (1996), citados por Hoeflich (2000), apresentam o conceito de cadeias produtivas como sendo um conjunto de componentes integrados, envolvendo fornecedores de serviços e insumos, indústrias de processamento e transformação, distribuição e comercialização, além de consumidores finais de produtos.

Haguenauer (2001) conceitua a cadeia produtiva como o conjunto das atividades, nas diversas etapas de processamento ou montagem, que transforma matérias-primas básicas em produtos finais.

Por outro lado, Bahia (2015) estabelece que cadeia produtiva é um conjunto articulado de atividades ou operações econômicas, técnicas, comerciais e logísticas, das quais resulta um produto ou serviço final. Ou, ainda, a sucessão das relações fornecedor-cliente, estabelecidas em todas as operações de produção e comercialização necessárias à transformação de insumos em produtos ou serviços, usados com satisfação pelo cliente final. Assim, Bahia (2015) define de maneira mais ampla o significado de cadeias produtivas, ao demonstrar que estas são, na verdade, um conjunto de atividades ou operações de ordem econômica, técnica, comercial e logística articuladas, que originam um produto ou serviço final. Costa; Nunez (2017, p. 34) salientam:

A industrialização e comercialização entram como aspectos bem relevantes na cadeia produtiva..., pois com a industrialização há uma materialidade da relação sociedade e natureza e com a comercialização o produto desse trabalho (valor de troca) chega ao consumidor final, criando valor de uso e valorando a natureza, como fonte de matéria-prima via mercado e consolidado pela propaganda/publicidade.

Portanto, as cadeias produtivas objetivam atender o consumidor final com produtos de qualidade e quantidade necessárias e com preços competitivos. Por esse motivo, para Castro et al. (1996), citados por Hoeflich (2000), é forte a influência do consumidor final sobre os componentes da cadeia e é importante conhecer as demandas desse mercado consumidor para garantir a sustentabilidade da cadeia produtiva.

\section{O Surgimento da Indústria Moveleira}

No contexto da cadeia produtiva moveleira, a indústria de móveis é um dos principais elos. Apesar dos referenciais teóricos não identificarem uma data precisa sobre quando e como surgiu esta indústria no mundo, sabe-se que o seu desenvolvimento se originou da produção artesanal para atender as necessidades de vida do homem, levando-se em consideração a forma de habitação, os costumes, a cultura e a sobrevivência.

A indústria de móveis originou-se a partir da produção artesanal de móveis na Europa durante a Idade Média, sendo que a produção era realizada em oficinas familiares e o conhecimento do processo produtivo era transferido de geração a geração.

Segundo Branco (1983), surge nesta época, na Inglaterra, uma preocupação mais específica para que o móvel atendesse as finalidades a que se destinava (escrivaninhas para escrever, cadeiras para sentar etc.). Mais tarde, a Revolução Industrial deu novo significado a essa indústria. 
De acordo com Bottini; Batista (2013), a Revolução Industrial - ocorrida na Europa no século XVIII - incrementou a produção industrial e transformou o trabalho artesanal em trabalho assalariado, além de ser responsável pela grande urbanização ocorrida na época.

Já no Brasil, a produção de móveis surgiu juntamente com a chegada dos primeiros colonos europeus, quando houve a necessidade deste tipo de atividade, pois a maioria deles que aqui desembarcou não tinha móveis. Isso proporcionou a que eles buscassem produzir seu próprio mobiliário, dando início, assim, às primeiras extrações de madeira nativa para utilização neste processo.

Tipicamente artesanal, a produção se estendeu durante muitos anos e somente no início do século XX, com o crescimento das principais cidades, como São Paulo e Rio de Janeiro, foi iniciado o processo de produção seriada e em larga escala. O Brasil, na década de 1930, começa a deixar sua condição histórica de país agrário e, conforme Bayeux (1997, p. 91), na esteira das inúmeras mudanças econômicas ocorridas no panorama internacional naquela época, "houve os primeiros indícios internos de industrialização".

Durante muito tempo as empresas localizadas nestas regiões obtiveram pouco crescimento e trabalhavam em grande parte para atender o mercado sob encomenda e na própria região. E estes móveis eram produzidos com madeira maciça e quase sempre sob medida, encomendados pelos consumidores brasileiros. Com o crescimento das cidades, o mercado de móveis ficou cada vez mais promissor e algumas regiões do país foram impulsionadas para a formação de polos moveleiros, em que cada uma apresentava as suas próprias particularidades, apresentando necessidades e características diferentes.

Apesar das indústrias do setor moveleiro se originarem em 1875, conforme Nascimento (2015) a indústria de móveis mundial é constituída, principalmente, por pequenas empresas, que, até os anos 50, atendiam quase que exclusivamente ao mercado interno dos seus países de origem. Apenas em meados da década de 50 teve início o comércio internacional de móveis, consolidando-se na década de 70 .

A partir da década de 1980, as mudanças na vida da população, associadas às transformações na indústria moveleira, como novas tecnologias e matérias-primas, foram responsáveis pela criação de diversos tipos de móveis.

Segundo Almeida; Ferreira; Maia (2019), a indústria moveleira apresenta numerosos processos de produção, utilizando diversos tipos de matérias-primas e resultando numa variedade de produtos finais, podendo ser classificada em função dos materiais com que os móveis são fabricados (madeira, metal e outros); também de acordo com os usos (móveis para residências ou para escritório).

O setor moveleiro nacional apresentou um grande crescimento nos últimos anos e o processo de produção de móveis no Brasil está evoluindo, com tecnologias que são comparadas aos níveis internacionais e com qualidade para competir em qualquer parte do mundo.

\section{Matéria-prima para a Indústria Moveleira}

No Brasil, a indústria moveleira é composta por micro e pequenas empresas dispersas geograficamente. Os móveis de madeira são a principal produção nacional, sendo que podem se dividir em retilíneos e torneados, diferenciados pelos detalhes e acabamentos. A principal matéria-prima utilizada na fabricação da maioria dos móveis é a madeira, de base florestal ou processada, mas também se confeccionam móveis com vários materiais, principalmente o metal, o plástico, o vime, 
a pedra e complementares, caso do tecido e da borracha.

Hoje, as exigências legais para o uso da madeira no país geram enormes cuidados da indústria moveleira brasileira no que se refere à utilização desta matéria-prima. Conforme BRASIL (2017), Programa Nacional de Florestas (PNF), está ocorrendo desequilíbrio entre a oferta e a demanda de madeira para atender as indústrias nos próximos anos. Para dar conta das necessidades de todos os ramos do setor madeireiro industrial, são cortados, aproximadamente, 450.000 hectares por ano de florestas de pinho e de eucalipto e a reposição anual, por meio do reflorestamento, não é maior do que 150.000 hectares. Neste ritmo de uso, o país verá o esgotamento da madeira para este fim em poucos anos.

A saída tem sido a utilização de novas matérias-primas para a elaboração do móvel, caso das madeiras oriundas de reflorestamento. O Brasil, neste caso, tem muitas vantagens competitivas pela quantidade de florestas plantadas. No entanto, seu uso adequado encontra, ainda, as seguintes dificuldades e/ou realidade: facilidade de acesso às flo- restas nativas; escassez de fornecedores no plantio especializado; poucos investimentos no desenvolvimento de projetos e no design de móveis, ocasionando baixa demanda da indústria por novos materiais; e carência na relação da indústria moveleira com o consumidor final, afetando a identificação de novas tendências de mercado.

Com relação ao uso do eucalipto, por exemplo, são recentes os investimentos das indústrias de celulose e papel com o objetivo de elaborar matéria-prima para a indústria moveleira. Os elevados custos na secagem da madeira e a sua recente utilização na indústria moveleira brasileira inibem maiores investimentos nessa área. A seguir, são destacados os principais tipos de madeira utilizados na cadeia moveleira brasileira.

\section{Madeira de Base Florestal}

A madeira de base florestal pode ser nativa ou de origem de reflorestamentos. No entanto, algumas espécies da madeira nativa estão em risco de extinção. A madeira oriunda de

Figura 1 - Cadeia Produtiva da Madeira

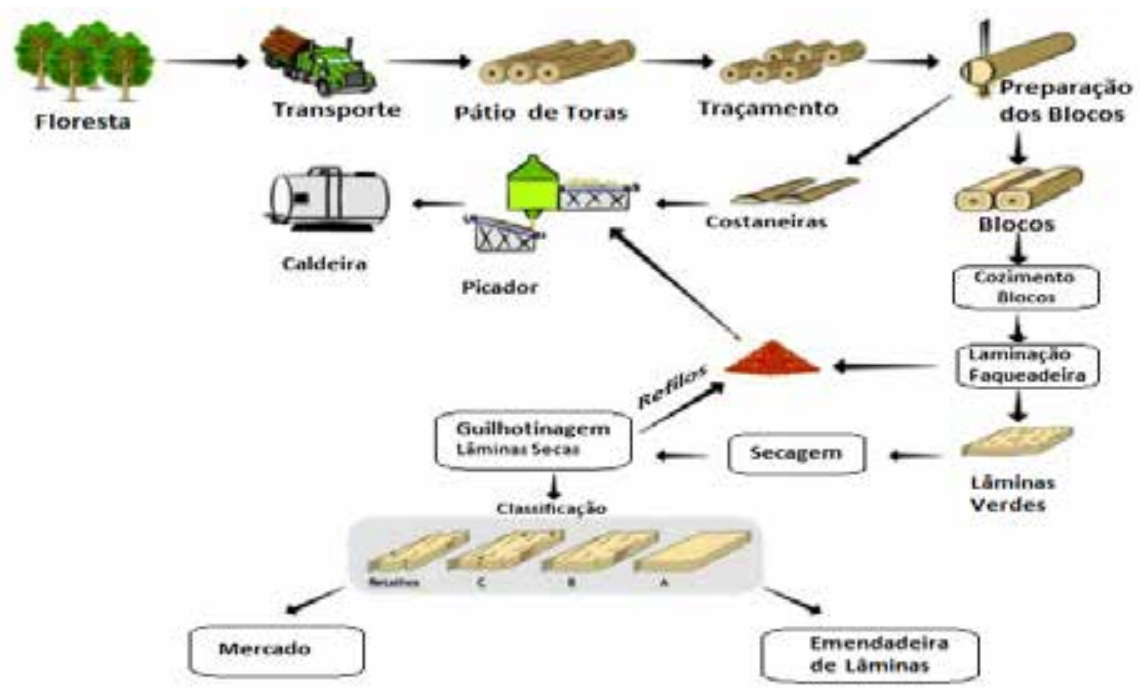

Fonte: VERDÉRIO JÚNIOR (2015, p. 26) 
reflorestamento (espécies como o pinho e o eucalipto) tem se apresentado como alternativa para a indústria moveleira. Conforme $\operatorname{SEBRAE}$ (2016, p. 1):

Atualmente, as espécies mais utilizadas para a fabricação de mobília são pínus e eucalipto, já que madeiras nativas utilizadas antigamente não podem ser retiradas da mata. Essas árvores são classificadas com relação a alguns aspectos, que apontam qual tipo de madeira pode ser utilizada para diferentes tipos de móveis.

A Figura 1 demonstra a estrutura da cadeia produtiva da madeira, uma das componentes da cadeia moveleira geral.

\section{Madeira Processada}

A matéria-prima obtida por meio da madeira processada é resultado da trituração de madeira maciça em pequenas fibras, e a mistura destas com outras substâncias químicas. Posteriormente, esta mistura passa por processo de compressão, de laminação, de colagem e de secagem em temperatura e pressão elevadas, conforme mostra a Figura 2.

Segundo AGEFLOR (2017), a madeira processada, utilizada na fabricação de partes de móveis, divide-se em:

a) madeira aglomerada, com qualidade bem rudimentar, apresentando densidade e durabilidade bem menores, usada para tampos de mesas, laterais de portas e de armários, racks, divisórias e estantes;

b) madeira serrada, também com qualidade rudimentar, usada em laterais de gavetas, estruturas de cadeiras, de sofás e de camas, molduras, embalagens, pés de mesas, estrados e acabamentos de móveis, tampos de mesas, partes frontais e laterais de balcões;

c) madeira compensada, com qualidade melhorada, apresenta densidade e durabilidade maiores, usada em fundos de gavetas e de armários, roupeiros, tampos de mesas, partes laterais de móveis, braços de sofás e prateleiras;

d) chapa de madeira compensada de média densidade e de qualidade elevada, apre-

Figura 2 - Cadeia Produtiva da Madeira Processada (MDF)

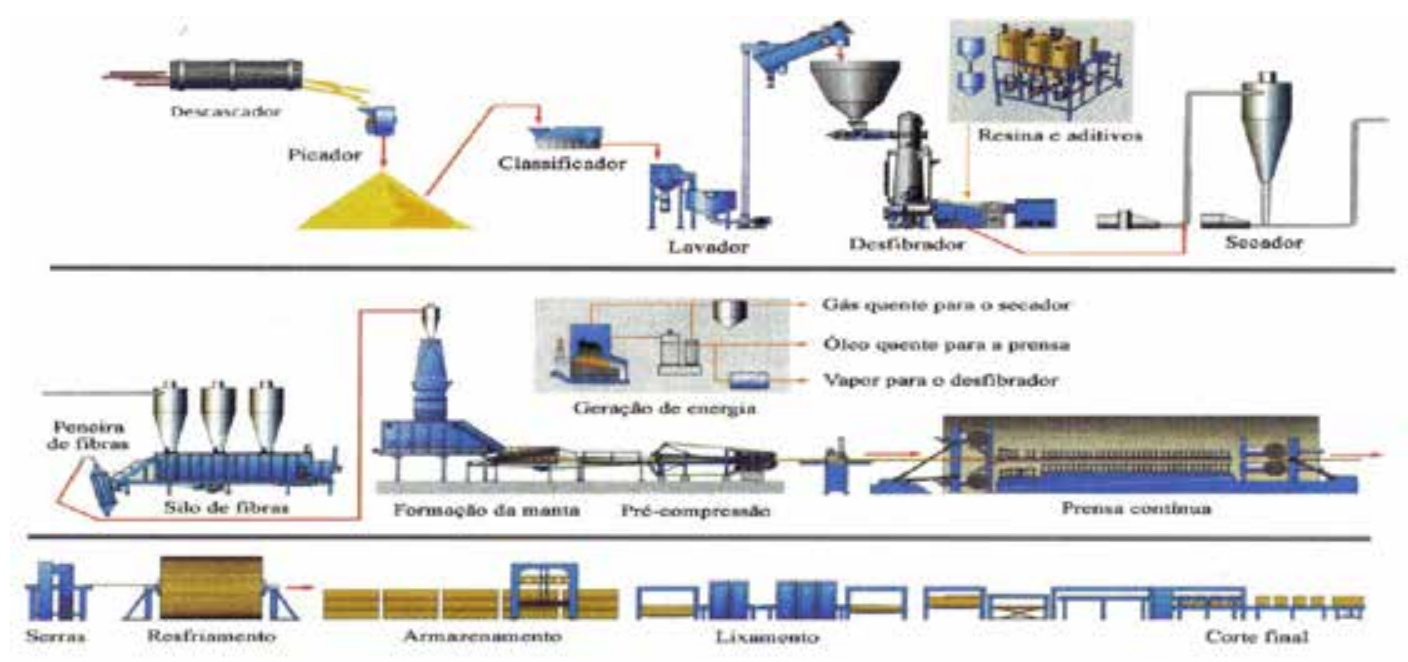

Fonte: CAMPOS; LAHR (2002, p. 2056) 
senta maior espessura e durabilidade, usada em componentes frontais, internos e laterais de móveis, fundos de gavetas, estantes, tampos de mesas e racks;

e) chapa de madeira compensada dura com alta qualidade parecida à madeira maciça, apresenta maior espessura e mais homogênea, usada em fundos de gavetas, de armários e de racks, tampos de móveis, móveis para uso infantil e divisórias.

\section{Os Polos Moveleiros da Região Sul do Brasil}

Segundo eMóbile (2019), na região Sul do Brasil a indústria moveleira apresenta um elevado número de empresas responsáveis por $86,2 \%$ dos valores exportados no período.

A indústria moveleira regional, ainda segundo eMóbile (2019), destaca-se pela boa participação nas exportações. Os três estados do Sul do país participam com um volume de mais de $80 \%$ das exportações brasileiras. Este elevado desempenho apresentado pelas empresas, principalmente as do Rio Grande do Sul e as de Santa Catarina, no mercado externo, acontece em função da busca por especialização neste setor, associada à qualidade e ao preço baixo dos produtos. A motivação pelo comércio externo surgiu nos anos 1980 , período em que o mercado interno enfrentava restrições econômicas.

Conforme Sperotto (2015), a região Sul apresenta integração entre a indústria e instituições de ensino e pesquisa, centros tecnológicos e de treinamento, que contribui em inovações e na melhoria da capacitação da mão de obra para as indústrias.

Ainda, segundo Sperotto (2015), o expressivo número de empresas moveleiras na região ocorreu devido às características de colonização. No período entre os anos de 1950 e 1960 havia, na região, uma grande área de floresta de araucária, madeira ideal para a fabricação de móveis, associada à experiência dos colonizadores, principalmente italianos e alemães, além de necessitar pouco investimento em infraestrutura.

De acordo com AGEFLOR (2017), as indústrias moveleiras foram organizadas em polos moveleiros, que concentram elevado número de empresas, como fornecedores e prestadores de serviços ligados ao setor, formando a cadeia produtiva moveleira. A proximidade dessas empresas constitui ganhos de concorrência para as mesmas, pois diminui seus custos de produção, havendo maior disponibilidade de matéria-prima e de mão de obra especializada, além da proximidade com os canais exportadores do Mercosul.

\section{O Setor Moveleiro Gaúcho}

Conforme o site eMóbile (2018), o Brasil tem 19,6 mil empresas moveleiras. Dessas, 2.700 estão sediadas no Rio Grande do Sul, o que equivale a $13,3 \%$ dos empreendimentos do setor no Brasil. As indústrias de móveis gaúchas produziram, aproximadamente, 85,3 milhões de peças, faturaram $\mathrm{R} \$ 6,73$ bilhões e exportaram mais de US\$ 183 milhões. Também foram responsáveis pela geração de mais de 35.000 postos de emprego.

Em 2017, segundo o site eMóbile (2018), as indústrias moveleiras gaúchas responderam por $18,8 \%$ do total de móveis fabricados no país e por $31,1 \%$ das exportações. Essa participação confere ao estado a segunda posição na produção nacional de móveis, conforme a Tabela I.

Atualmente, a produção se dá a partir de madeira extraída de florestas plantadas. Essas florestas gaúchas estão distribuídas em sete polos, conforme a Figura 3, em torno dos quais se instalaram indústrias que promovem o desenvolvimento das respectivas regiões. A cadeia produtiva de base florestal gera bens e serviços à sociedade, destacando-se por ofe- 
recer importantes contribuições nos aspectos econômico, social e ambiental.

Tabela I - Maiores produtores de móveis do Brasil

\begin{tabular}{cc}
\hline $\begin{array}{c}\text { Maiores produtores de móveis do } \\
\text { Brasil/estado }\end{array}$ & Percentual \\
\hline São Paulo & $23,5 \%$ \\
Rio Grande do Sul & $18,8 \%$ \\
Paraná & $14,6 \%$ \\
Minas Gerais & $14 \%$ \\
Santa Catarina & $11,3 \%$ \\
Demais estados & $17,8 \%$ \\
\hline
\end{tabular}

Fonte: Elaboração própria a partir de dados de eMóbile, 2018

A Serra Gaúcha é composta principalmente por plantações de pínus; as regiões Central e Sudeste do estado, por plantações de acácia-negra, pínus e eucalipto; o Litoral Médio também tem como espécie principal o pínus; a Região do Alto Uruguai é composta por plantações de pínus e eucalipto; o Sul e a Campanha, por eucalipto e acácia-negra; e a Fronteira Oeste, por eucalipto e pínus.

Figura 3 - Florestas Plantadas no Rio Grande do Sul

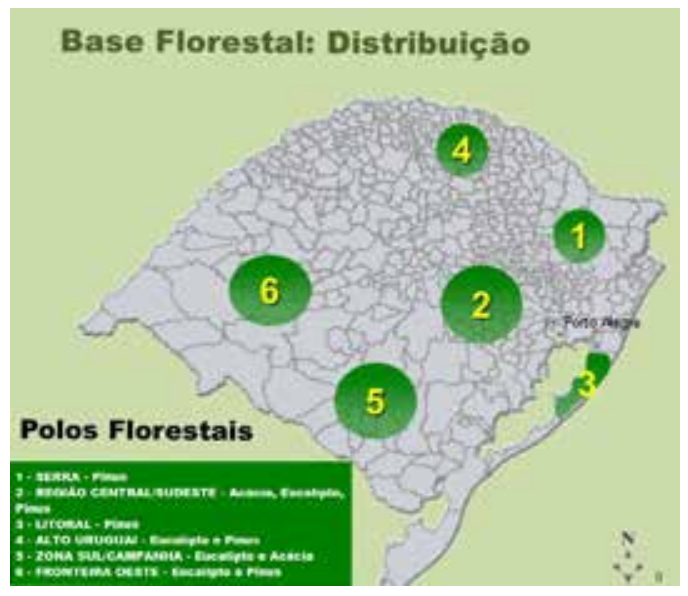

Fonte: AGEFLOR (2011), Engenheiro Florestal, Dr. Doádi Antonio Breda
Quanto à participação na economia, o estudo da AGEFLOR (2016) aponta que, em 2014, o setor de base florestal (madeiras, móveis, celulose e derivados) contribuiu com $7 \%$ da geração de empregos, $3 \%$ da arrecadação de impostos e com $2 \%$ do valor de venda de produtos de base florestal exportados pelo Rio Grande do Sul. O estudo coloca que, no estado gaúcho, são cerca de 2.300 empresas que integram a cadeia produtiva à base de plantios florestais, com destaque para o segmento de móveis de madeira, que concentra 95\% destas, em polos como Bento Gonçalves e Lagoa Vermelha. Já na Região Metropolitana de Porto Alegre, encontram-se as principais empresas de painéis de madeira e de celulose.

As oportunidades são favorecidas pela aproximação dos fabricantes gaúchos com redes internacionais para melhor distribuição de seus produtos. A aproximação com designers internacionais promove o intercâmbio com outras preferências e tendências do resto do mundo. A criação de linhas exclusivas, em parceria com designers famosos, oferece a possibilidade de maior visibilidade e novos mercados aos produtores gaúchos e, em contrapartida, oferece, aos designers internacionais e seus canais de distribuição, produtos únicos, com a qualidade que caracteriza os móveis gaúchos. Segundo Federação das Indústrias do Estado do Rio de Janeiro - Sistema FIRJAN (2015, p. 8):

Além da tecnologia, outros fatores de competitividade da indústria de móveis relacionam-se com novas matérias-primas, design, especialização da produção, estratégias comerciais e de distribuição, entre outros. A dinâmica das inovações baseia-se, principalmente, naquelas que se referem ao produto, através do aprimoramento do design e da utilização de novos materiais. 
Portanto, a indústria deve se adequar às normas e atender as exigências do consumidor para proporcionar a melhoria da qualidade dos produtos finais, tornando-se cada vez mais competitiva.

\section{Cadeia Produtiva Moveleira}

A indústria moveleira é caracterizada pela utilização de vários processos de produção e diferentes matérias-primas na geração de uma diversidade de produtos finais.

A organização da cadeia produtiva de móveis reúne vários processos de produção, iniciando na extração de matérias-primas diversificadas, como madeiras brutas das áreas florestais, algodão e minérios. Posteriormente, ocorre a transformação, em diferentes indústrias, das matérias-primas elaboradas, como tábuas de madeira maciça, chapas de madeira processada, metais, plásticos, tecidos, entre outros. Finalmente, ocorre a fabricação dos móveis na indústria moveleira e sua venda aos lojistas e ao consumidor final.

Conforme Sperotto (2016), estão presentes, na cadeia produtiva moveleira, os fornecedores de insumos, entre os quais podemos destacar: a extração e a produção de painéis e lâminas de madeira; as placas, corrediças, trilhos e tubos de metal; os componentes de acrílico, vidro e metal; para pintura as tintas, lacas e vernizes; e materiais para estofamento, como couros e tecidos. Também fazem parte do elo as máquinas e equipamentos. $\mathrm{Na}$ jusante da cadeia, encontram-se as etapas especializadas, como os da pesquisa e desenvolvimento de design, o treinamento da mão de obra e, por fím, o transporte, montagem e distribuição para os mercados interno e externo.

No topo da cadeia moveleira encontra-se o fornecedor de madeira, que pode utilizar florestas nativas ou de reflorestamento. Atualmente, a madeira proveniente de reflorestamento é apontada como principal matéria-prima no Brasil, a qual abastece grande parte da indústria moveleira. A Figura 4 retrata a

Figura 4 - Estrutura da Cadeia Produtiva Moveleira

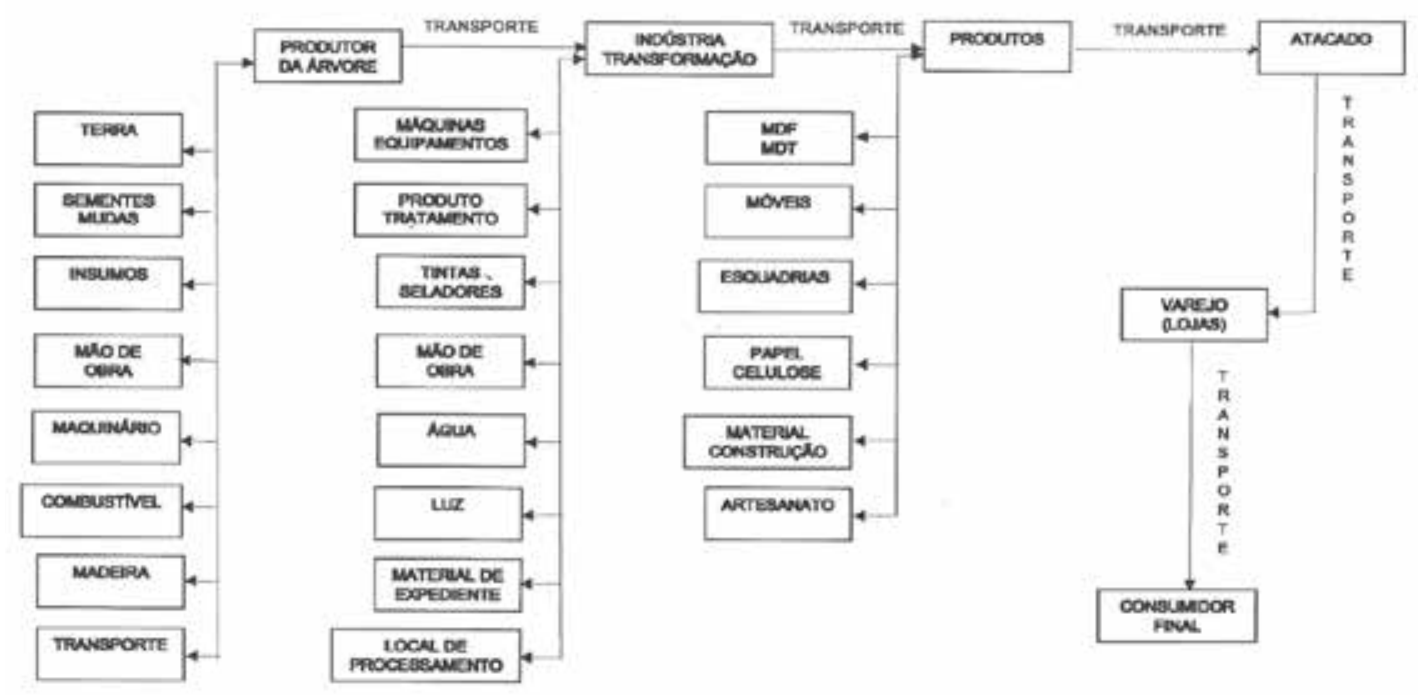

Fonte: Elaboração própria a partir de dados do SEBRAE (2018) 
estrutura da cadeia moveleira no Brasil em geral e no Rio Grande do Sul em particular.

Os painéis, os laminados e as esquadrias formam em conjunto as principais matérias-primas na cadeia moveleira. Conforme o SEBRAE (2014), os blocos de madeira sólida (compensados e lâminas) e os reconstituídos (aglomerados, MDF, chapas, OSB e HDF) são considerados os produtos mais importantes deste elo. Outro elo importante na indústria moveleira é composto pelos laminados e esquadrias metálicas. Além desses, também se tem os elos da matéria-prima como fibras, pregos, tubos, colas, vidros, seladores, vernizes e tintas, elementos fundamentais para a elaboração de móveis. Ainda de acordo com o SEBRAE (2008, p. 14):

[...] a utilização destes produtos na indústria moveleira varia muito, dependendo do estilo de móveis produzidos. Alguns vernizes são acabamentos de alta resistência química e física, que conferem características de maior resistência à peça e secagem por luz ultravioleta rápida. Por sua vez, as colas são insumos pouco utilizados na fabricação de móveis em série.

$\mathrm{Na}$ cadeia moveleira existem, ainda, os elos relacionados ao sistema de transporte, máquinas e equipamentos para extração e produção de madeira para o seu beneficiamento na indústria. Também são encontradas as matérias-primas provenientes da indústria de plásticos, couro, tecido e produtos de metal. As máquinas e equipamentos mais utilizados na cadeia principal são serras elétricas e tratores utilizados no corte de árvores, de florestas nativas ou áreas reflorestadas; serras, prensas e outros instrumentos utilizados no tratamento da madeira e na produção de aglomerados; máquinas de modelagem de móveis, instrumentos tradicionais de marcenaria e carpintaria.

No final da cadeia produtiva moveleira se encontram os elos que envolvem produtos que também estão no início da cadeia, dentre os quais se destacam a energia elétrica e a água. A cadeia geral ainda pode ser composta, no seu final, pela indústria de papel e celulose.

\section{Considerações Finais}

Atualmente, num mundo globalizado, as empresas organizam-se para trabalhar em rede, sendo uma maneira de prosperar e, em alguns casos, até de sobreviver. Hoje, trabalhar isolado de seus fornecedores é atrasar a empresa, especialmente em termos de desenvolvimento e inovação.

Neste contexto, a compreensão e inserção das atividades em cadeias produtivas se torna fundamental. Além disso, a relação entre cadeias produtivas diversas, porém complementares, passa a ser uma necessidade.

No setor moveleiro, diversos elementos têm contribuído para o surgimento e aumento de cadeias produtivas. Dentre eles destaca-se a ampliação de um mercado competitivo, levando a fortalecer o relacionamento entre empresas, com parcerias; a expansão do uso da tecnologia; e o uso mão de obra qualificada.

Os elos da cadeia produtiva de móveis reúnem empresas ligadas a diversos processos de produção, iniciando na extração de matérias-primas diversificadas, como madeiras brutas das áreas florestais, passando pela transformação das mesmas em matérias-primas elaboradas, como tábuas de madeira maciça, chapas de madeira processada, as quais se somam a metais, plásticos, tecidos, dentre outros, oriundos de diferentes indústrias fornecedoras. Este conjunto de elementos, que se constituem em diferentes elos da cadeia, levam ao elo da fabricação de móveis pela indústria moveleira.

No Brasil, a indústria de móveis apresenta-se bem distribuída. Entretanto, as re- 
giões Sul e Sudeste apresentam uma cadeia moveleira mais desenvolvida, concentrando a maioria dos empregos formais do setor e contribuindo para o desenvolvimento de tal cadeia.

A indústria moveleira brasileira é regionalmente concentrada, com formação de polos regionais junto aos estados de São Paulo, Rio Grande do Sul, Santa Catarina e Paraná, os quais respondem por $68,2 \%$ da produção nacional de móveis, sendo que São Paulo apresenta o maior volume individual de produção, com $23,5 \%$ do total, seguido do Rio Grande do Sul, com 18,8\% da produção nacional. Em sua maioria, as empresas da cadeia do setor moveleiro são micro, pequenas e médias indústrias.
A cadeia moveleira investe na formação de mão de obra qualificada visando ao desenvolvimento de produtos que atendam com maior competitividade o mercado externo. Nota-se, igualmente, a ausência de políticas nacional e estadual mais consistentes que balizem o funcionamento da cadeia moveleira geral, desde o reflorestamento de áreas agrícolas, até a entrega final do produto no atacado ou ao consumidor final.

Convém destacar o caráter limitado desta investigação, visto que é desejável a sua ampliação e continuidade, pois, apesar da forte evolução na compreensão do funcionamento da cadeia moveleira, o setor, no Brasil, ainda precisa avançar mais na sua adequação às necessidades e preferências do mercado consumidor, que se modificam constantemente.

\section{REFERÊNCIAS}

AGEFLOR - Associação Gaúcha de Empresas Florestais. A indústria de base florestal no Rio Grande do Sul: Ano Base 2015. Curitiba: Consufor, 2016.

AGEFLOR - Associação Gaúcha de Empresas Florestais. Sustentabilidade das Florestas

Plantadas no RS. Porto Alegre, 2011.

AGEFLOR - Associação Gaúcha de Empresas Florestais. A indústria de base florestal no Rio Grande do Sul 2017: Ano Base 2016. Porto Alegre: RDK Logs Ltda, 2017.

ALMEIDA G.; FERREIRA M. A. S.; Maia W. F. O. Contribuição do ecodesign ao setor moveleiro: Análise de resíduos do polo moveleiro de Ubá. Mediação - Educação e Humanidades Universidade do Estado de Minas Gerais - Unidade Ubá. Vol. IV, 2019.

BAYEUX, G. O Móvel da Casa Brasileira. São Paulo: Museu da Casa Brasileira, 1997.

BAHIA, L. D. O Efeito na Evolução da Produtividade do Trabalho da Indústria Brasileira Devido a Mudanças Tecnológicas nas suas Cadeias Produtivas (1990-2009). Texto para discussão, n. 2068. Instituto de Pesquisa Econômica Aplicada - Ipea, 2015.

BOTTINI L. M.; BATISTA, R. L. O trabalho da mulher durante a revolução industrial inglesa (1780 a 1850). Os desafios da escola pública paranaense na perspectiva do professor PDE. v.1, 2013. Disponível em: http://www.diaadiaeducacao.pr.gov.br/portals/cadernospde/pdebusca/producoes pde/2013/2013_fafipa_hist_artigo_lucia_mamus_bottini.pdf. Acesso em: 08 maio 2020.

BRANCO, A. A. Para uma maior compatibilização entre móveis e usuários. Revista Madeira/ Móveis, v.1, n.1, p.18-26, 1983.

BRASIL. Ministério do Meio Ambiente (MMA). Programa Nacional de Florestas (PNF) 2017. 
Brasília, DF, 2017. Disponível em: https://www.mma.gov.br/florestas/programa-nacional-de-florestas Acesso em: 08 maio 2020.

CAMPOS, C. I; LAHR F. A. R. MDF - Processo de produção, propriedades e aplicações. CBECIMAT - Congresso Brasileiro de Engenharia e Ciência dos Materiais. Natal, 2002.

COSTA R. C.; NUNEZ C. V. Cadeias produtivas \& seus ambientes. Manaus: INPA, 2017.

EMÓBILE. Setor moveleiro em 2017 registra alta de 0,3\% na produção. Disponível em: http:www. emobile.com.br/site/setor-moveleiro/setor-moveleiro-brasil-móveis-2018. Acesso em: 06 jul. 2019.

EMÓBILE. Produção de móveis 2019. Disponível em: http:www.emobile.com.br/site/setormoveleiro/setor-moveleiro-brasil-móveis- 2020. Acesso em: 06 maio 2020.

FIEP - Federação das Indústrias do Estado do Paraná. Panorama Setorial: indústria de móveis: Paraná 2017. Curitiba: Fiep, 2017.

FIRJAN - Federação das Indústrias do Estado do Rio de Janeiro. Pesquisa Diagnóstico da Indústria Moveleira da FIRJAN. Rio de Janeiro, 2015.

HAGUENAUER, L. Competitividade: conceitos e medidas. Rio de Janeiro: TDIEI/UFRJ, 2001.

HOEFLICH, V. Material Didático do Curso de Pós-Graduação em Agronegócio. Módulo IV. Universidade Federal do Paraná. 2000.

MONFORT, J. La recherche des filiéres de production. Economié et Documents. Anais [...] n 67. INSEE, França, 93p. 1983.

MOVERGS - Associação das Indústrias de Móveis do Estado do Rio Grande do Sul. Setor moveleiro Gaúcho, 2015. Disponível em: movergs.com.br. Acesso em: 21 jan. 2018.

NASCIMENTO, S. V. do. Análise do Desempenho das Movelarias do Município de Parintins. 2015. 113 f. Dissertação (Mestrado em Engenharia de Produção) - Faculdade de Tecnologia da Universidade Federal do Amazonas, Manaus, AM, 2015.

SEBRAE - Serviço Brasileiro de Apoio às Micro e Pequenas Empresas, 2008. Cadeia produtiva da indústria madeiro-moveleira: cenários econômicos e estudos setoriais. Disponível em: http:// www.sebrae-rs.com.br/institucional.aspx. Acesso em: 17 fev. 2019.

SEBRAE - Serviço Brasileiro de Apoio às Micro e Pequenas Empresas, 2014. Normas técnicas na cadeia produtiva do setor moveleiro de pequenos negócios. Disponível em: http://www.sebrae-rs. com.br/institucional.aspx. Acesso em: maio 2020.

SEBRAE - Serviço Brasileiro de Apoio às Micro e Pequenas Empresas, 2016. Comércio e serviços: madeira e móveis planejados. Disponível em: http://www.sebrae-rs.com.br/institucional. aspx. Acesso em: maio 2020.

SELMANI, Y. Analyse de Flux Phiysique de Bois a L'Interieur de La Filiere. École Nationale du Genie Rural des Eaux et des Fôrets - ENGREEF. Nancy 200 p. 1992.

SPEROTTO, F.Q. A aglomeração produtiva de móveis no Corede Serra: relatório II. Porto Alegre: FEE, 2015. Relatório do projeto Estudo de Aglomerações Industriais e Agroindustriais no RS. Disponível em: http://www.agdi.rs.gov.br/?model=conteudo\&menu=960. Acesso em: 7 abr. 2019.

SPEROTTO, F. Q. Arranjo produtivo local móveis da Serra Gaúcha. In: MACADAR, B.

M. de; COSTA, R. M. da. (Org.). Aglomerações e arranjos produtivos Locais no Rio Grande do Sul. Porto Alegre: FEE, 2016. P. 405- 443. Disponível em: https://www.fee.rs.gov.br/wp-content/ uploads/2016/11/20161109livro-apls-arranjo-produtivolocal-mcentveis-da-serra-gacha.pdf. Acesso em: 17 jul. 2017.

VERDÉRIO JÚNIOR, S. A. Madeira: propriedades físicas e processos de fabricação. Bauru: FEB, 2015. 